\title{
Analysis of T and NK cells immune response in Ipilimumab treated Melanoma patients
}

\author{
Rossana Tallerico ${ }^{1}$, Costanza M Cristiani ${ }^{1}$, Mariaelena Capone ${ }^{2}$, Gabriele Madonna ${ }^{2}$, Domenico Mallardo², \\ Ester Simeone ${ }^{2}$, Andrea Dominijanni ${ }^{3}$, Antonio M Grimaldi ${ }^{2}$, Francesco Colucci ${ }^{4}$, Paolo A Ascierto ${ }^{2}$, \\ Ennio Carbone $e^{1,5^{*}}$
}

From Melanoma Bridge Meeting 2014

Naples, Italy. 03-06 December 2014

\section{Background}

The most promising immunotherapeutics tested in metastatic melanoma patients are the monoclonal antibody blocking CTLA-4 (Ipilimumab), and those interfering with PD-1 and PD-L1. However, the lack of knowledge on predictive biomarkers that could assist the treatment remains a limiting factor. We speculate that, along with additional markers, the immunoscore [1] is fundamental as prognostic and predictive marker for response to immunotherapies in metastatic melanoma. Our previous data demonstrate that NK cells control the melanoma progression $[2,3]$. Therefore we have analysed both T cells and NK cells subsets frequencies and receptors repertoire in the peripheral blood of Ipilimumab treated patients with Stage IV metastatic melanoma.

\section{Material and methods}

Peripheral blood mononuclear cells (PBMCs) from 12 different patients with stage IV metastatic melanoma were collected and analyzed. Each patient received 4 infusions of Ipilimumab each 21 days. Before each infusion we collected patients' blood and isolated PBMCs to analyze the lymphocytes compartment.

We stained for the following antibodies: CD56 PE, CD3 Fitc, CD56 APC, CD4 PeCy7, CD8 APCCy7, CD152 (CTLA4) PE, CD279 (PD-1) PE, CCR7 PeCy7, CD158a/h (KIR2DL1/S1) PE, CD158b (KIR2DL2/DL3) PE, CD158e (KIR3DL1) PE, CD16 APCCy7, CD57 PE, CD69 PE, CD314 (NKG2D) PE, CD226 (DNAM-1) PE, CD337 (NKp30) PE, CD336 (NKp44) PE, CD335 (NKp46) PE (Miltenyi Biotech), CD192 (CCR2) AlexaFluor 647,

\footnotetext{
${ }^{1}$ Tumorimmunology and Immunopathology Laboratory, Department of Experimental and Clinic Medicine, University "Magna Graecia" of Catanzaro, Campus - Germaneto, 88100 Catanzaro Italy

Full list of author information is available at the end of the article
}

CXCR2 (IL8RB) APC, 7-AADStaining Solution (BD Italia), TIM3 PE (ebioscience), NKG2C PE (R\&D Systems). The analysis was performed with FACS CANTO II. Statistical analysis was performed with Anova and Student's t-test.

\section{Results}

Our data indicate that, after the first Ipilimumab treatment, an inversion of CD4/CD8 ratio occurs with a concomitant increase in the CD56 ${ }^{\mathrm{dim}}$ population and a higher expression of TIM-3 and NKp46 molecules on the surface of NK cells. Moreover, the frequency of NK and T cells expressing KIRs and CCR7 is reduced, while the mean fluorescence intensity of CD16 and PD1 is upregulated on both CD56 ${ }^{\text {bright }}$ and CD56 ${ }^{\text {dim }}$ NK cells.

\section{Conclusions}

These preliminary data indicate that early during Ipilimumab treatment, cytotoxic lymphocytes $\mathrm{CD} 8^{+} \mathrm{T}$ cells and CD56 ${ }^{\mathrm{dim}}$ NK cells expand and become activated. NK cells seem to be polarized towards a CD56 ${ }^{\mathrm{dim}} \mathrm{CD} 16^{\mathrm{bright}}$ $\mathrm{KIRs}^{+} \mathrm{NKp} 46^{+} \mathrm{TIM}^{+}$phenotype. Ipilimumab treatment may induce NK cells maturation, which might in turn drive activation of $\mathrm{CD}^{+} \mathrm{T}$ cells.

\footnotetext{
Authors' details

${ }^{1}$ Tumorimmunology and Immunopathology Laboratory, Department of Experimental and Clinic Medicine, University "Magna Graecia" of Catanzaro, Campus - Germaneto, 88100 Catanzaro Italy. ${ }^{2}$ Melanoma.

Cancerlmmunotherapy and Innovative Therapy Unit, Istituto Nazionale Tumori Fondazione "G. Pascale", Via Mariano Semmola, 80131 Napoli -Italy. ${ }^{3}$ Immunohaematological Transfusion Medicine Centre "Pugliese-Ciaccio" Hospital of Catanzaro, 88100 Ctanzaro, Italy. ${ }^{4}$ Department of Obstetrics and Gynaecology, University of Cambridge Clinical School, Cambridge, UK. ${ }^{5}$ Department of Microbiology Cell and Tumorbiology (MTC), Karolinska Institutet, Nobelvag 16, 17077 Stockholm, Sweden.
} 


\section{References}

1. Galon J, Pagès F, Marincola FM, Thurin M, Trinchieri G, Fox BA, Gajewski TF, Ascierto PA: The immune score as a new possible approach for the classification of cancer. J Trans/ Med 2012, 10:1.

2. Lakshmikanth T, Burke S, Ali TH, Kimpfler S, Ursini F, Ruggeri L, Capanni M, Umansky V, Paschen A, Sucker A, Pende D, Groh V, Biassoni R, Höglund P, Kato M, Shibuya K, Schadendorf D, Anichini A, Ferrone S, Velardi A, Kärre K, Shibuya A, Carbone E, Colucci F: NCRs and DNAM-1 mediate NK cell recognition and lysis of human and mouse melanoma cell lines in vitro and in vivo. J Clin Invest 2009, 119(5):1251-1263.

3. Burke S, Lakshmikanth T, Colucci F, Carbone E: New views on natural killer cell-based immunotherapy for melanoma treatment. Trends Immunol 2010, 31(9):339-345.

doi:10.1186/1479-5876-13-S1-08

Cite this article as: Tallerico et al:: Analysis of T and NK cells immune response in Ipilimumab treated Melanoma patients. Journal of Translational Medicine 2015 13(Suppl 1):O8.

\section{Submit your next manuscript to BioMed Central} and take full advantage of:

- Convenient online submission

- Thorough peer review

- No space constraints or color figure charges

- Immediate publication on acceptance

- Inclusion in PubMed, CAS, Scopus and Google Scholar

- Research which is freely available for redistribution

Submit your manuscript at www.biomedcentral.com/submit 